\title{
DOES THE PLACEMENT OF A FREE CONNECTIVE TISSUE GRAFT IN CONJUNCTION WITH IMMEDIATELY PLACED DENTAL IMPLANTS IN FRESH EXTRACTION SOCKETS PRESERVE THE LABIAL MARGINAL BONE LEVEL? A RANDOMIZED CONTROLLED CLINICAL TRIAL
}

\author{
Ahmed Reda * and Mohamed A. El Baz **
}

\begin{abstract}
Background: The beneficial effects of simultaneous soft tissue augmentation along with immediate post-extraction implant placement in the esthetic zone have been clearly demonstrated regarding the preservation and maintenance of soft tissue architecture. However, the potential of soft tissue augmentation to preserve the vertical height of thin labial bone plates is not fully evident. Research question: Is it necessary to apply a soft tissue graft with immediate implants in the esthetic zone if preservation of the height of a thin labial plate is desired? Methods: Twenty patients with single hopeless teeth in the esthetic zone having thin facial bone plates $(<2 \mathrm{~mm})$ were equally and randomly divided into 2 groups; (A) who received immediate implants only (control) and (B) who received immediate implants and connective tissue graft secured over the implant in split-thickness facial and palatal pouches (test). Amount of vertical marginal bone loss from the facial plate was measured over 6 months. Results: A statistically-significant difference (at $\mathrm{P} \leq 0.05$ ) existed between the mean values of vertical bone loss of both groups. The amount of vertical bone loss was limited more in the test group (B). Conclusion: Simultaneous soft tissue augmentation with immediate implants in the esthetic zone demonstrated beneficial effects regarding the preservation of the vertical level of thin labial plates.
\end{abstract}

KEY WORDS: Immediate implants; esthetic zone; marginal bone loss; connective tissue graft; thin biotype

\section{INTRODUCTION}

Traditionally, missing teeth have long been replaced with fixed or removable partial dentures to restore various functions as phonetics, mastication and, of outmost importance, esthetics when the maxillary inter-premolar zone is addressed ${ }^{(1,2)}$. Several authors stated that placing dental implants to replace missing teeth offer several advantages over

* Associate Professor of Periodontology, Oral Medicine and Diagnosis, Faculty of Dentistry, Cairo University

**Lecturer of Oral and Maxillofacial Surgery, Faculty of Dentistry, October University for Modern Sciences and Arts (MSA) 
conventional prosthetics since the tooth structure is preserved. Other numerous studies reported high patient satisfaction following dental implants procedures regarding function and esthetics and their willingness to repeat the procedure again if other teeth are to be replaced. Various long-term studies proved that oral rehabilitation of partially or fully edentulous patients with dental implants is a superior treatment option, therefore, dental implants are considered nowadays the first choice for replacing missing teeth. ${ }^{(3,4)}$

Immediate implant placement in fresh extraction sockets of hopeless teeth serves to shorten the whole treatment period and has been proven to exhibit similar survival rates to implant placement in healed bony sites. ${ }^{(5-7)}$

Despite all the advantages of immediate implant placement, some drawbacks exist; namely the unavoidable vertical and horizontal bone resorption following the tooth extraction, especially on the expense of the facial plate. This is followed by some negative soft tissue changes that adversely affect the short and long-term esthetics around the immediately-placed dental implant. These effects are usually more evident in patients with thin tissue biotype. ${ }^{(8-11)}$

Many long-term studies have linked the quality and quantity of crestal soft tissue to the amount of bone loss facial to the implants, especially in the esthetic zone, therefore, the use of free connective tissue grafts for soft tissue augmentation around dental implants has been widely investigated. Several investigators highlighted the importance of the presence of a soft tissue profile with abundant connective tissue around the implant to serve as a biological seal and complement esthetics. The presence of thick tissue is of importance also for the maintenance of integrity of the bony cuff around the dental implant, especially on the facial aspect. These considerations are of particular importance when the implant is placed initially having a thin labial shell of bone, which is the case when an immediate implant is placed in an extraction socket where thin tissue biotype exists. ${ }^{(12-22)}$

However, despite of many existing reliable studies, there is no consensus regarding whether it is crucial to augment the soft tissue in conjunction with immediate post-extraction implant placement, if the marginal bone is to be preserved and hence, the level of the facial marginal peri-implant mucosa.

\section{AIM}

This study aimed at evaluating whether it is necessary to augment the soft tissue in conjunction with immediate implant placement in the esthetic zone if the labial marginal bone level is to be preserved, prior to implant loading.

\section{METHODOLOGY}

\section{Patients' recruitment}

Twenty patients with a single hopeless tooth in the esthetic zone were recruited for this trial, regardless of their gender. All patients were informed about the study, required procedures, expected outcomes and possible complications. All patients signed a detailed consent before participation.

\section{Inclusion criteria}

1. Patients with a single hopeless tooth in the esthetic zone.

2. Patients not in the growing age.

3. Medically fit for minor surgical oral procedures and negative history of diseases that may contraindicate implant placement.

4. Absence of history of administration of drugs that may affect the healing process.

5. Free of periodontal disease.

6. Absence of local pathological conditions in the operatory zone. 
7. Non-smokers.

8. Free of drug abuse or abnormal psychological conditions.

9. Adequate inter-arch space to accommodate for the future prosthesis.

10. Thin labial bone $(<2 \mathrm{~mm})$; assessed through the pre-operative Cone Beam Volumetric Tomographic evaluation (CBVT).

\section{Patients' grouping and randomization}

Recruited patients were randomly allocated into 2 groups; with ten patients each. Group (A) received immediate implants only and was assigned as the control group, while group (B) received immediate implants in conjunction with free connective tissue grafts and was assigned as the test group.

\section{Pre-operative assessment and preparation}

Thorough clinical evaluation was done to evaluate the periodontal parameters and confirm the absence of periodontal disease and local pathological conditions. Pre-operative (CBVT) evaluation confirmed the previous findings and was used to determine the proximity to the regional anatomical structures and assess the appropriate implant dimensions and placement position. All patients received regular prophylactic procedures

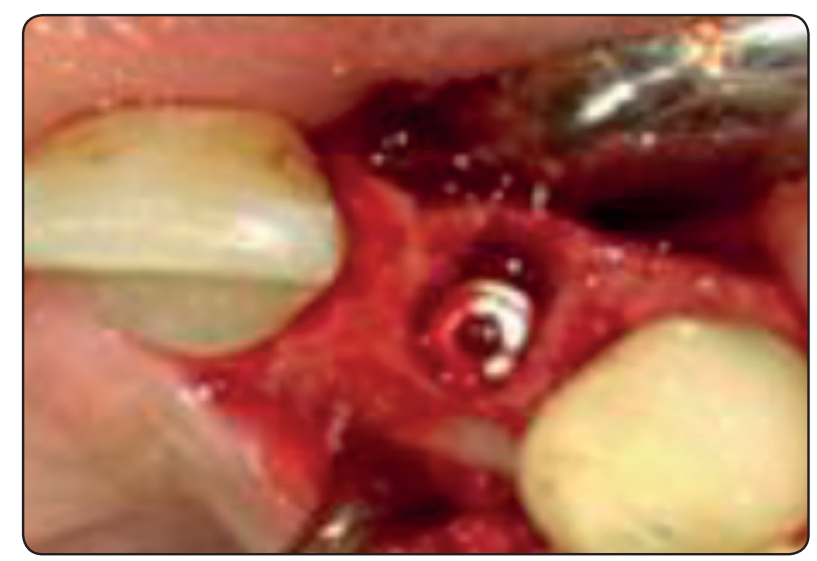

Implant placement leaving a jumping gap $>2 \mathrm{~mm}$ and pouches preparation (scaling, polishing and reinforcement of oral hygiene measures) one week prior to the commencement of the surgical steps.

\section{Surgical procedures}

For both groups, a minimal crestal flap was raised to just expose the marginal bone after administration of local anaesthesia using infiltration with Articaine hydrochloride $4 \%$ with 1:100000 Adrenaline tartrate as a vasoconstrictor. The hopeless tooth was then atraumatically extracted with the help of periotomes (Hu-friedy, PT1, USA). After checking the integrity of the osseous walls of the extraction socket, patients then received immediate dental implants (Legacy 3, Implant Direct, USA), placed in a palatal position and $2 \mathrm{~mm}$ apical to the labial bone crest. After the procedures ended in both groups, the crestal tissues were secured back to their original position using 5/0 resorbable sutures. All patients received regional (CBVT) examinations in the same day of the procedures, from which the baseline measurements of the level of labial marginal bone were recorded in reference to the most crestal point of the placed implant.

For the test group, a free sub-epithelial connective tissue graft of average thickness $2 \mathrm{~mm}$ was harvested from the hard palate through a single-incision technique. A split-thickness pouch was prepared on

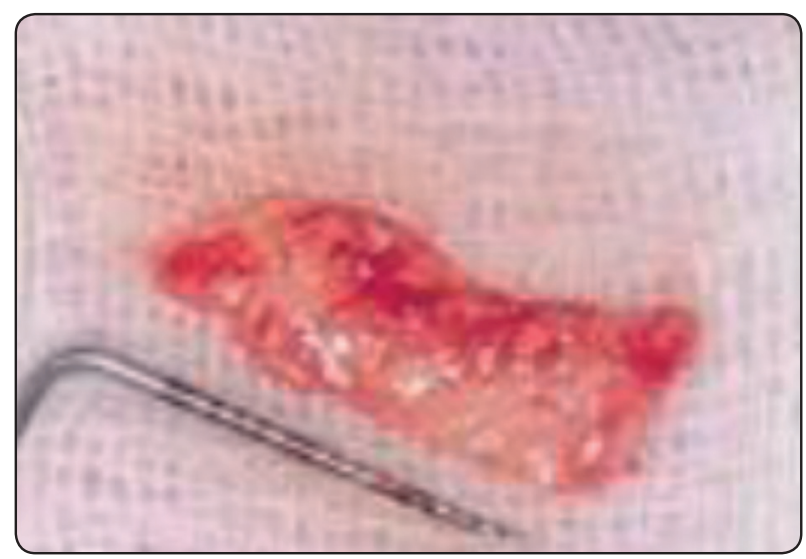

Harvested Connective Tissue Graft from the palate 


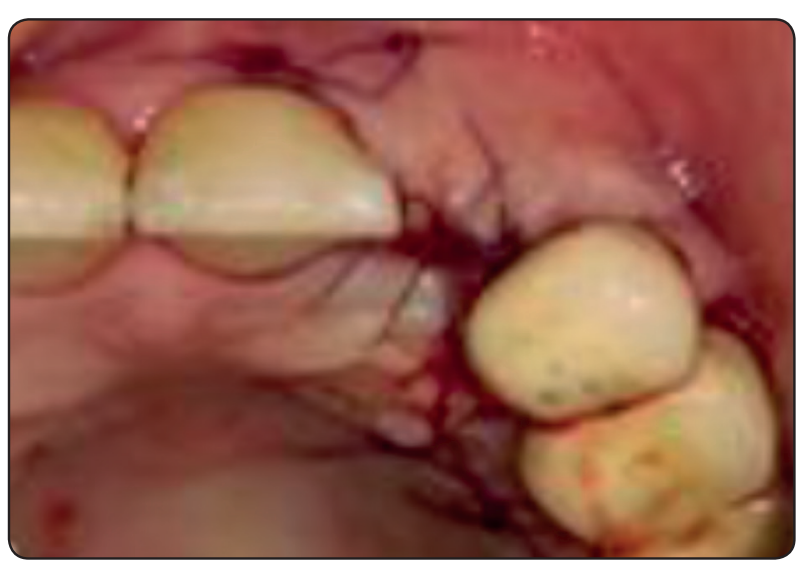

Connective Tissue Graft secured within the prepared pouches

both the facial and palatal aspects of the implant, into which the harvested connective tissue graft was secured via apical and proximal sutures using $5 / 0$ resorbable filaments. Care was taken so that the soft tissue graft extended at least $3 \mathrm{~mm}$ apical to the labial bone margin and tucked within the palatal pouch. The palatal donor site was then closed using multiple interrupted 4/0 black silk sutures.

\section{Patient instructions and follow-up}

Patients were instructed to avoid trauma to the surgical site and advised to use pain killers (Brufen $600 \mathrm{mg}$ every 12 hours) for the first 3 days and to be continued up to one week if needed. No local or systemic antibiotics were prescribed. Sutures were removed after 10 days and patients were examined thereafter every one month, where the mucosal and neighbouring gingival conditions were assessed and oral hygiene measures were reinforced. Mechanical plaque debridement was performed whenever necessary. The study extended for 6 months and all patients agreed not to receive any form of temporary tooth replacements throughout the study period. A regional (CBVT) was requested after 6 months to evaluate labial marginal bone changes, and then the second stage surgery was performed to expose the submerged implants and place an appropriate healing collar for 2-3 weeks. Prosthetic phase was then finished within the next 5 days.

\section{RESULTS}

All placed implants exhibited the clinical and radiographic signs of successful osseointegration after a healing period of 6 months. All surgical sites demonstrated uneventful healing and patients complained only of mild tolerable pain during the first 2 post-operative days.

Patients' data are demonstrated in tables (1) and (2):

TABLE (1): Data for group (A)

\begin{tabular}{|c|c|c|c|c|}
\hline $\begin{array}{c}\text { Patient } \\
\text { no. }\end{array}$ & Age & Gender & $\begin{array}{c}\text { Implant diameter } \\
(\mathbf{m m}) \text { /Tooth no. }\end{array}$ & $\begin{array}{c}\text { Labial marginal } \\
\text { gap (mm) }\end{array}$ \\
\hline 1 & 23 & F & $\mathbf{3 . 2} / \mathbf{1 3}$ & $>2$ \\
\hline 2 & 26 & F & $\mathbf{3 . 7} / \mathbf{2 1}$ & $>2$ \\
\hline 3 & 29 & M & $\mathbf{4 . 2 / 2 5}$ & $>2$ \\
\hline 4 & 32 & F & $\mathbf{3 . 7 / 1 5}$ & $>2$ \\
\hline 5 & 28 & M & $\mathbf{3 . 7} / \mathbf{2 3}$ & $>2$ \\
\hline 6 & 36 & M & $\mathbf{3 . 2} / \mathbf{1 1}$ & $>2$ \\
\hline 7 & 48 & F & $\mathbf{3 . 7} / \mathbf{1 1}$ & $>2$ \\
\hline 8 & 52 & F & $\mathbf{4 . 2 / 2 1}$ & $>2$ \\
\hline 9 & 64 & F & $\mathbf{3 . 2} / \mathbf{2 2}$ & $>2$ \\
\hline 10 & 27 & M & $\mathbf{3 . 7} / \mathbf{1 3}$ & $>2$ \\
\hline
\end{tabular}

*Mean age (36.5 years)

$* M / F$ ratio $=2: 3$

TABLE (2): Data for group (B)

\begin{tabular}{|c|c|c|c|c|}
\hline $\begin{array}{c}\text { Patient } \\
\text { no. }\end{array}$ & Age & Gender & $\begin{array}{c}\text { Implant diameter } \\
(\mathbf{m m}) \text { Tooth no. }\end{array}$ & $\begin{array}{c}\text { Labial marginal } \\
\text { gap (mm) }\end{array}$ \\
\hline 1 & 22 & M & $\mathbf{3 . 7} / \mathbf{2 3}$ & $>2$ \\
\hline 2 & 45 & F & $\mathbf{3 . 2} / \mathbf{2 4}$ & $>2$ \\
\hline 3 & 65 & F & $\mathbf{3 . 2} / \mathbf{1 1}$ & $>2$ \\
\hline 4 & 43 & F & $\mathbf{3 . 2} / \mathbf{1 4}$ & $>2$ \\
\hline 5 & 21 & F & $\mathbf{3 . 7} / \mathbf{2 5}$ & $>2$ \\
\hline 6 & 34 & M & $\mathbf{4 . 2} / \mathbf{2 2}$ & $>2$ \\
\hline 7 & 46 & M & $\mathbf{4 . 2} / \mathbf{2 2}$ & $>2$ \\
\hline 8 & 28 & F & $\mathbf{3 . 7} / \mathbf{1 1}$ & $>2$ \\
\hline 9 & 32 & M & $\mathbf{3 . 2} / \mathbf{1 2}$ & $>2$ \\
\hline 10 & 36 & M & $\mathbf{3 . 7} / \mathbf{2 2}$ & $>2$ \\
\hline
\end{tabular}

$*$ Mean age $=37.2$ years

$* M / F$ ratio $=1: 1$ 


\section{Statistical analysis:}

Data were presented as means and standard deviation values. Facial vertical marginal bone level change data showed normal distribution, so parametric tests were used for comparison. Paired t-test was used to compare between the measurements.

The significance level was set at $\mathrm{P} \leq 0.05$.

Statistical data are presented in table (3):

TABLE (3): Statistical data of both groups

\begin{tabular}{|c|c|c|c|c|c|}
\hline & \multicolumn{2}{|c|}{ Mean } & \multicolumn{2}{c|}{$\begin{array}{c}\text { Standard } \\
\text { Deviation }\end{array}$} & \multirow{2}{*}{ P-value } \\
\cline { 2 - 5 } & Control & Test & Control & Test & \\
\hline $\begin{array}{c}\text { Vertical marginal } \\
\text { bone loss of labial } \\
\text { plate (mm) }\end{array}$ & 1.66 & 1.26 & 0.87 & 0.64 & $0.004^{*}$ \\
\hline
\end{tabular}

*Significant at $P \leq 0.05$

\section{DISCUSSION}

Marked bone resorption takes place following tooth extraction. An average of $4.4 \mathrm{~mm}$ horizontal bone loss and $1.2 \mathrm{~mm}$ vertical bone loss was found to take place in the first six months following tooth extraction ${ }^{(23)}$. Animal studies have also shown that following tooth extraction, the buccal and lingual walls of the alveolar process undergo substantial resorption. This may lead to difficulty in the future placement of dental implants as well as aesthetic problems due to the variation of the anatomy of the residual ridge that may worsen the quality and prognosis of the final restoration ${ }^{(24)}$.

Implants placed directly into fresh extraction sites with or without barrier membranes may preserve the bony architecture, and they were found to be predictably successful and to reduce the time from tooth extraction to complete rehabilitation, when compared to classical delayed and late implantation protocols. It was suggested that the resorption of the thin buccal wall and the alveolar crest after extraction may be delayed by a timely insertion of the implant and longer and wider implants can be placed early compared to late implantation procedure ${ }^{(25)}$.

However, questions were raised about the fact that immediate implantation can preserve alveolar bone dimension following tooth extraction and some authors stated that although immediate implant placement is considered a predictable treatment modality, it does not preserve the alveolar ridge dimension and that bone resorption takes place at the buccal and lingual plates of bone ${ }^{(26,27)}$.

Another controversial issue was whether to graft the jumping gap that occurs between the implant body and the internal socket wall. Some authors reported that gaps exceeding $2 \mathrm{~mm}$ lack the potential to heal with bone formation and that a fibrous connective tissue capsule will be found between the implant body and the socket wall ${ }^{(32)}$, while others reported that the marginal gaps around immediate implants can heal with substantial bone gain from the inside of the defect and concomitant bone resorption from outside of the defect ${ }^{(26,27)}$.

Care was taken during this study to place the implant in a palatal position and leave a horizontal labial jumping-gap distance exceeding the critical threshold of $2 \mathrm{~mm}$, to eliminate this parameter from the analysis. All gaps healed uniformly, however, the horizontal dimensional changes were not addressed and were not within the scope of this study.

Although controversial, crestal and facial soft tissue quality and quantity have long been linked to marginal bone loss around dental implants and the risk of development of future inflammatory complications. Of course, these concerns are magnified when an implant is placed in a fresh extraction socket with thin facial bony plate, and, the challenge is greater when the esthetic zone is addressed. Recently, the importance of the presence of thick connective tissue profile on the facial aspect of the dental implant gained a supreme attention. The presence of thick connective was 
clearly demonstrated to positively affect the longterm stability of the soft tissue architecture $\mathrm{a}^{(33,35-37)}$. However, the direct effect of enhancing the soft tissue profile with connective tissue grafts on preserving the vertical height of a thin labial plate of an extraction socket and subsequent marginal tissue position changes is not clear till present.

The present study was conducted to demonstrate whether the simultaneous thickening of the soft tissue around an immediately placed implant in a fresh extraction socket will preserve the vertical height of the thin labial bone plate and prevent early marginal bone loss or not. Hence, the aim of this investigation was to assess the importance and/or the necessity of simultaneous soft tissue augmentation, when immediately-placed dental implants are addressed in the esthetic zone.

The present study was limited to the esthetic zone. The presence of a thin labial plate $(<2 \mathrm{~mm})$ was necessary for patient inclusion to unify the conditions and parameters. Careful case selection in terms of excluding patients with systemic diseases, smokers and any patient with acute infections was followed in this study to exclude conditions that may affect osseointegration and compromise bone fill of the marginal defects around the implants. Although chronic infections at the implant sites are not considered a risk factor for immediate implant placement as proven by several human and animal studies (28-30), patients with chronic infections were also excluded from the study to eliminate other variables during results' analysis.

During this study, evaluation of the extraction socket prior to immediate implant placement was carried out with extreme caution and only sockets belonging to Type I extraction sockets were selected. These sockets have an intact buccal plate of bone and adequate bone below it to allow for achieving high primary implant stability.

The twenty placed implants were successfully osseointegrated and healing was uneventful. The palatal donor sites in the test group healed normally as well. No local or systemic antibiotics were prescribed to eliminate any variables that may affect the healing process. None of the patients reported the need for pain killers after 3 days.

Neither approach followed in this study was able to completely prevent the vertical bone loss after tooth extraction. The mean value of vertical bone loss from the labial plate in the control group was $1.66 \mathrm{~mm}$ while that for the test group was $1.26 \mathrm{~mm}$. This finding was in agreement with those results reported throughout the literature ${ }^{(26,27)}$. However, despite the presence of only a little difference in the mean values of amount of vertical bone loss of the labial plate $(0.4 \mathrm{~mm})$ in favour of the test group, this difference was found to be statistically significant.

Controversially, some studies contradicted this conclusion and stated that the soft tissue profile did not affect the marginal bone changes around dental implants ${ }^{(34,38,39)}$. However, the interpretation of this previous finding can be advocated by Sclar A in 2003, whose work highlighted the positive effect of the presence of thick connective tissue around dental implants regarding the maintenance of their bony housing and also the effect of the harvested periosteum within the graft with its induction capabilities and its ability to speed-up the filling of the jumping gap by creating a cellular pool of osteoblasts that may involve the formation of new bone. The stabilizing effect of the soft tissue graft over the blood clot should also be taken into consideration. The presence of thick soft tissue is also linked to improved inter-related vasculature around and within the alveolar bone ${ }^{(31)}$.

\section{CONCLUSIONS}

Within the limitations of this study, it can be concluded that;

1. Simultaneous augmentation with autogenous free connective tissue grafts in conjunction with immediate post-extraction implants is beneficial regarding the preservation of the bone height of thin labial plates. 
2. Both procedures, when done simultaneously, shorten the treatment time and decrease the need for additional steps during the implant uncovery later-on.

However, larger sample size and further clinical trials are recommended to validate these outcomes and conclusions.

\section{REFERENCES}

1. Branemark PI, Hansson BO, Adell R, Breine U, Lindstrom $\mathrm{J}$, Hallen O, Ohman A; Osseointegrated implants in the treatment of the edentulous jaw: Experience from a 10 year period; Scand J of plast and reconstr surg Suppl; 16:1-132, 1977.

2. Adell R, Lekholm U, Rockler B; A 15 year study of Osseointegrated implants in the treatment of the edentulous jaw; Int J Oral surgery; 10: 387 -416, 1981.

3. Branemark PI; Osseointegration and its experimental background; J Prosthet Dent; 50(3): 399-410, 1983.

4. Albrektsson T. Bone tissue response. In: Bränemark PI, Zarb G, Albrektsson T. eds. Tissue Integrated Prostheses: Osseointegration in Clinical Dentistry. Chicago:Quintessence; 129-143, 1985.

5. Amler MH, Johnson PL, Salman I; Histological and histochemical investigation of human alveolar socket healing in undisturbed extraction wounds; J Am Dent Assoc; 61: 32-44, 1960.

6. Brazilay I. Immediate implants: there current status. Int I Prosttiodont; 6:169-175, 1993.

7. Akimoto K, Becker W, Persson R, Baker D, Rohrer M, O'Neal R; Evaluation of Titanium Implants Placed into Simulated Extraction Sockets: A Study in Dogs; Int J Oral Implants; 14(3):351-360, 1999.

8. Botticellin D, Berglundh T, Lindhe J; Hard-tissue alterations following immediate implant placement in extraction sites; J Clin Periodontol; 31(10): 820-828, 2004.

9. Araujo MG, Lindhe J; Dimensional ridge alterations following tooth extraction. An experimental study in the dog; J Clin Periodontol; 32(2): 212-8, 2005.

10. Becker W, Sennerby L, Bedrossian E, Becker B E, Lucchini J P; Implant stability measurements for implants placed at the time of extraction: a cohort prospective clinical trial; J Periodontol; 76: 391-397, 2005.
11. Araújo M, Wennström J, Lindhe J; Modeling of the buccal and lingual bone walls of fresh extraction sites following implant installation; Clin Oral Implants Res; 17(6): 606$614,2006$.

12. Buser D, Martin W, Belser UC; Optimizing esthetics for implant restorations in the anterior maxilla: anatomical and surgical considerations; Int J Oral Maxillofac Implants; 19: 43-61, 2004.

13. Chen S, Buser D; Clinical and esthetic outcomes of implants placed in postextraction sites; Int J Maxillofac Implants; 24: 186-217, 2009.

14. Chen ST, Darby IB, Adams GG, Reynolds EC; A prospective clinical study of bone augmentation techniques at immediate implants; Clin Oral Implants Res; 16: 176-184, 2005.

15. Chen ST, Wilson TG JR, Hämmerle $\mathrm{CH}$; Immediate or Early Placement of Implants Following Tooth Extraction: Review of Biologic Basis, Clinical Procedures, and Outcomes; Int J Oral Maxillofac Implants; 19(7): 12-25, 2004.

16. Choquet V, Hermans M, Adriaenssens P, Daelemans P, Tarnow DP, Malevez C; Clinical and radiographic evaluation of the papilla level adjacent to single-tooth dental implants. A retrospective study in the maxillary anterior region; J Periodontol; 72(10): 1364-71, 2001.

17. Rosa R, Juan C, Ángel M, Jesús R, Gilberto S, José L, Rafael G; Soft Tissue Augmentation Techniques in Implants Placed and Provisionalized Immediately: A Systematic Review; Biomed Res Int. 2016

18. Gupta S, Deo V, Williams C; Interproximal Papillae Reconstruction around Implant Using Subepithelial Connective Tissue Graft in Maxillary Anterior Region: A Case Series; J Oral Maxillofac Res. 2012 Apr-Jun; 3(2): e1

19. Irinakis T, Aldahlawi S; The dome technique: a new surgical technique to enhance soft- tissue margins and emergence profiles around implants placed in the esthetic zone; Clin Cosmet Investig Dent. 2018; 10: 1-7

20. Kaushik A, Pal PK, Jhamb K, Chopra D, Chaurasia V, Vinaykumar S, Suresh DK, Babaji P; Clinical Evaluation of Papilla Reconstruction Using Subepithelial Connective Tissue Graft; J Clin Diagn Res. 2014 Sep; 8(9): ZC77ZC81.

21. Wouter G, Gerry M, Elise G, Ronald E, Henny J, Mühlemann $S$; Immediate placement and provisionalization of implants in the aesthetic zone with or without a connec- 
tive tissue graft: A 1-year randomized controlled trial and volumetric study; Clin Oral Implants Res. 2018 Jul; 29(7): 671-678

22. S. G. Jyothi, M. G. Triveni, D. S. Mehta, K. Nandakumar ; Evaluation of single-tooth replacement by an immediate implant covered with connective tissuegraft as a biologic barrier; J Indian Soc Periodontol. 2013 May-Jun; 17(3): 354-360

23. Bays RA; The pathophysiology and anatomy of edentulous bone loss, In: Davis WH, Ed. Reconstructive preprosthetic oral and maxillofacial surgery, Philadelphia PA: Saunders: 1-17, 1986.

24. Gelb DA; Immediate implant surgery: three-year retrospective evaluation of 50 consecutive cases: Int J Oral Maxillofac Implants; 8: 388-399, 1993.

25. Denissen HW, Kalk W, Veldhuis HA, van Waas MA; Anatomic consideration for preventive implantation: Int J Oral Maxillofac Implants; 82: 191-196, 1993.

26. Botticellin D, Berglundh T, Lindhe J; Hard-tissue alterations following immediate implant placement in extraction sites; J Clin Periodontol; 31(10): 820-828, 2004.

27. Araújo M, Wennström J, Lindhe J; Modeling of the buccal and lingual bone walls of fresh extraction sites following implant installation; Clin Oral Implants Res; 17(6): 606-614, 2006.

28. Casap N, Zeltser C, Wexler A, Tarazi E, Zeltser R; Immediate placement of dental implants into debrided infected dentoalveolar sockets: J oral Maxillofac Surg; 65: 384-92, 2007.

29. Lindeboom JA, Tjiook Y, Kroon FH; Immediate placement of implants in periapical infected sites: A prospective randomized study in 50 patients: Oral Surg Oral Med Oral Pathol Oral Radiol Endod; 101: 705-710, 2006.

30. Villa R, Rangert B; Immediate and early function of implants placed in extraction sockets of maxillary infected teeth: A pilot study: J Prosthet Dent; 97: S96-S108, 2007.
31. Sclar A; soft tissue and esthetic considerations in implant dentistry $1^{\text {st }}$ ed., Chicago, 2003.

32. Wilson TG JR, Carino J, Schenk R, Cochran D; Immediate implants covered with connective tissue membranes: $\mathrm{Hu}$ man biopsies: J Periodontol; 734: 402-409, 2003.

33. Grover HS, Yadav A, Yadav P, Nanda P; Optimizing Gingival Biotype Using Subepithelial Connective Tissue Graft: A Case Report and One-Year Followup; Case Rep Dent. 2011; 2011: 263813

34. Moghaddas H, Amjadi MR, Naghsh N; Clinical and biometrical evaluation of socket preservation using demineralized freeze-dried bone allograft with and without the palatal connective tissue as a biologic membrane; Dent Res J (Isfahan) 2012 Nov-Dec; 9(6): 758-763

35. Elkhaweldi A, Rincon Soler C, Cayarga R, Suzuki T, Kaufman Z; Various Techniques to Increase Keratinized Tissue for Implant Supported Overdentures: Retrospective Case Series; Int J Dent. 2015; 2015: 104903

36. Piero Pi, Giorgio P; The Use of a Novel Porcine Derived Acellular Dermal Matrix (Mucoderm) in Peri-Implant Soft Tissue Augmentation: Preliminary Results of a Prospective Pilot Cohort Study; Biomed Res Int. 2018; 2018: 6406051

37. Mihir Raghavendra Kulkarni, Purva Vijay Bakshi, Abhishek Somanath Kavlekar, Srinath Lakshman Thakur; Applications of a modified palatal roll flap in peri-implant soft-tissue augmentation - A case series; J Indian Soc Periodontol. 2017 Jul-Aug; 21(4): 333-336

38. Andreas L, Georgios A, Michelle G, Donald E, James E, Georgios E; Soft Tissue Surgical Procedures for Optimizing Anterior Implant Esthetics; Int J Dent. 2015; 2015: 740764

39. A Rokn, SH Bassir, AA Rasouli Ghahroudi, MJ Kharazifard, R Manesheof; Long-term Stability of Soft Tissue Esthetic Outcomes Following Conventional Single Implant Treatment in the Anterior Maxilla: 10-12 Year Results; Open Dent J. 2016; 10: 602-609 